\title{
Novel mutations associated with inherited human calcium-sensing receptor disorders: A clinical genetic study
}

\author{
Alejandro García-Castaño ${ }^{1, *}$, Leire Madariaga 1,2,*, Gustavo Pérez de Nanclares ${ }^{1,2}$, Gema Ariceta ${ }^{3}$, \\ Sonia Gaztambide ${ }^{1,2}$ and Luis Castaño $0^{1,2}$ on behalf of Spanish Endocrinology Group \\ and Renal Tube Group \\ ${ }^{1}$ Biocruces Bizkaia Health Research Institute, CIBERDEM, CIBERER, Barakaldo, Spain, ${ }^{2}$ Hospital Universitario Cruces, \\ UPV/EHU, Barakaldo, Spain, and ${ }^{3}$ Hospital Universitario Materno-Infantil Vall d'Hebron, Autonomous University of \\ Barcelona, Barcelona, Spain \\ *(A García-Castaño and L Madariaga contributed equally to this work) \\ Correspondence \\ should be addressed \\ to L Castaño \\ Email \\ LUISANTONIO. \\ CASTANOGONZALEZ@ \\ osakidetza.eus
}

\begin{abstract}
Objective: Molecular diagnosis is a useful diagnostic tool in calcium metabolism disorders. The calcium-sensing receptor (CaSR) is known to play a central role in the regulation of extracellular calcium homeostasis. We performed clinical, biochemical and genetic characterization of sequence anomalies in this receptor in a cohort of 130 individuals from 82 families with suspected alterations in the CASR gene, one of the largest series described.

Methods: The CASR gene was screened for mutations by polymerase chain reaction followed by direct Sanger sequencing.

Results: Presumed CaSR-inactivating mutations were found in 65 patients from 26 families. These patients had hypercalcemia (median: $11.3 \mathrm{mg} / \mathrm{dL}$ ) but normal or abnormally high parathyroid hormone (PTH) levels (median: 52 pg/ $\mathrm{mL}$ ). On the other hand, presumed CaSR-activating mutations were detected in 17 patients from eight families. These patients had a median serum calcium level of $7.4 \mathrm{mg} / \mathrm{dL}$ and hypoparathyroidism (median: PTH $13 \mathrm{pg} / \mathrm{mL}$ ). Further, common polymorphisms previously associated with high blood ionized calcium levels were found in 27 patients (median calcium: $10.6 \mathrm{mg} / \mathrm{dL}$; median PTH: $65 \mathrm{pg} / \mathrm{mL}$ ) with no other alterations in CASR. Overall, we found 30 different mutations, of which, 14 have not been previously reported (p.Ala26Ser, p.Cys60Arg, p.Lys119lle, p.Leu123Met, p.Glu133Val, p.Gly222Glu, p.Phe351Ile, p.Cys542Tyr, p.Cys546Gly, p.Cys677Tyr, p.Ile816Val, p.Ala887Asp, p.Glu934*, p.Pro935_Gln945dup).

Conclusions: Patients with CASR mutations may not fit the classic clinical pictures of hypercalcemia with hypocalciuria or hypocalcemia with hypercalciuria. Molecular studies are important for confirming the diagnosis and distinguishing it from other entities. Our genetic analysis confirmed CaSR disorders in 82 patients in the study cohort.
\end{abstract}

\section{Introduction}

Inherited human calcium-sensing receptor (CaSR) disorders are a rare heterogeneous group of genetic conditions that need to be distinguished from the more commonly observed calcium metabolism disorders with different origins. The CaSR (OMIM +601199) is known to play a central role in the regulation of extracellular calcium homeostasis $(1,2)$; specifically, in the presence of a high extracellular $\mathrm{Ca}^{+2}$ concentration $\left[\mathrm{Ca}^{+2}\right]$, the activation of CaSR inhibits the secretion of parathyroid hormone (PTH) (3), whereas the effect is reversed under low $\left[\mathrm{Ca}^{+2}\right]$ 
conditions $(3,4,5,6)$. Loss-of-function mutations in the CASR gene cause neonatal hyperparathyroidism (OMIM \#239200), hypocalciuric hypercalcemia type I (OMIM \#145980) and some cases of hypercalciuric hypercalcemia. Conversely, gain-of-function mutations in CASR cause autosomal dominant hypocalcemia (OMIM \#601198) and can also mimic a salt-wasting nephropathy described as autosomal dominant hypocalcemia with Bartter syndrome (OMIM \#601198) (7). Moreover, CaSR anomalies have been linked to susceptibility to idiopathic generalized epilepsy (OMIM \#612899), and some gene polymorphisms to high urinary calcium levels and an elevated risk of nephrolithiasis (8).

The CASR gene was mapped to chromosome 3q13.33-q21.1 (9) and encodes the G protein-coupled receptor CaSR. This gene is most abundantly expressed in the parathyroid gland and kidney, where it is found in all nephron segments (10). In addition, CASR is expressed in many other tissues and participates in numerous functions, some of them not well known, that induce cellular responses through the activation or inhibition of various signaling pathways (11).

Few series of patients with CASR mutations have been published to date; however, the increasing availability of genetic diagnosis underlines the need for greater awareness of this group of disorders. The aim of this study was to perform clinical, biochemical and genetic characterization of sequence anomalies in the CASR gene among a group of individuals presenting with abnormal serum calcium and/or PTH levels, in order to widen our knowledge of these rare entities. So far, according to the Human Gene Mutation Database (www.hgmd.cf.ac.uk), 397 mutations in the CASR gene have been described.

\section{Patients and methods}

\section{Ethics statement}

The study was approved by the Ethics Committee for Clinical Research of Euskadi (CEIC-E). Patients or, in the case of minors, their relatives or guardians provided written informed consent before inclusion in the study. Minors over 12 years also provided their assent.

\section{Population}

The CASR gene was screened for mutations in a cohort of 130 patients (79 females) from 82 different unrelated families. A total of 82 index cases were referred to our hospital for genetic testing based on the following criteria: the presence of hypocalciuric hypercalcemia or hypercalciuric hypocalcemia; hyperparathyroidism with recurrence of hypercalcemia after surgery or hypoparathyroidism with hypocalcemia (surgical causes or transient neonatal conditions associated with hypercalcemia, maternal diabetes, prematurity or neonatal asphyxia have been excluded) and a history of hypercalcemia or hypocalcemia in the family. The other 48 patients were referred based on family screening. Clinical diagnoses were made by adult and pediatric endocrinologists or nephrologists working in 38 different hospitals, most of them in Spain. Most patient biological samples $(n=114)$ were sent for genetic testing directly by the endocrinology or nephrology departments, but in some cases $(n=16)$, when the referring hospital was a member of RenalTube, a research network for primary tubulopathies (www. renaltube.com), samples were received through this network. In all cases, the genetic diagnoses ware made in the Molecular Genetic Laboratory at Biocruces Bizkaia Health Research Institute, Barakaldo, Spain.

\section{DNA analysis}

Extraction and purification of genomic DNA from peripheral blood leukocytes were performed according to the manufacturer's instructions (QIAamp DNA Blood Mini Kit, QIAGEN). The exon regions and flanking intronic sequences of the CASR gene (Ensembl identifiers: gene ENSG00000036828; transcript, ENST00000490131) were screened for mutations by PCR followed by direct Sanger sequencing of both strands.

We used primers to amplify exons 2-7 together with their splice sites for the CASR gene. All PCR analyses were performed in a total volume of $50 \mu \mathrm{L}$, with DMSO $10 \%$ (primer sequences and PCR conditions are available on request). PCR products were then purified with ExoSAP-IT (USB Cleveland, OH, USA) or by extracting them from agarose gels using QIAquick Gel Extraction Kits (QIAGEN), according to the manufacturer's specifications.

Purified amplified products were directly sequenced in both directions with fluorescent dideoxynucleotides (BigDye Terminator v3.1 Cycle Sequencing Kit, Life Technologies). We used internal primers for direct sequencing of exon 3 ( 2 primers), exon 4 ( 4 primers) and exon 7 (5 primers) for the CASR gene. In the remaining exons, the same primers as in the PCR were used for direct sequencing.

Excess dye terminators were removed (ethanol-EDTAsodium acetate) and samples were denatured and loaded 
onto an ABI3130xl Genetic Analyzer (Life Technologies). The potential effects of the mutations were investigated using pathogenicity prediction software: Mutation t@ sting (www.mutationtaster.org), PolyPhen-2 (www. genetics.bwh.harvard.edu), SIFT (www.sift.jcvi.org) and SNPs\&GO (www.snps-and-go.biocomp.unibo.it). DNA mutations were named according to the Human Genome Variation Society guidelines (www.hgvs.org).

\section{Statistical analysis}

In patients with alterations in the CASR gene, the relationships between calcium, PTH and age were assessed using linear regression. The analysis was performed with IBM SPSS, Statistics for Windows, version 23.

\section{Results}

In our cohort of 82 families, the index cases of 43 families (53\%) presented with hypercalcemia associated with normal or elevated serum PTH levels and hypocalciuria; 15 index cases, characterized by excessive secretion of PTH by parathyroid glands, high serum calcium levels and multigland hyperplasia, were diagnosed with hyperparathyroidism (18\%); three index cases had hypercalcemic normocalciuria (4\%) and three index cases had hypercalcemic hypercalciuria (4\%). On the other hand, the index cases of 11 families (13\%) exhibited hypocalcemia and low or normal serum PTH levels with hypercalciuria; six index cases had hypocalcemic normocalciuria (7\%); and finally, one index case had hypocalcemic hypocalciuria (1\%).

We found presumed CASR-inactivating mutations in 26 families (65 patients) (Table 1). Among these families, the index case in 20 families presented with the incidental finding of asymptomatic hypercalcemia and the clinical diagnosis was hypocalciuric hypercalcemia type I, whereas the index case in the other 6 families was initially diagnosed with primary hyperparathyroidism (Fig. 1).

In the group with presumed CASR-inactivating mutations, the median age at diagnosis of the disease was 24 years. Laboratory features included elevated serum calcium levels (median: $11.3 \mathrm{mg} / \mathrm{dL}$ ) but normal or abnormally high intact PTH levels (median: $52 \mathrm{pg} /$ $\mathrm{mL}$ ). Moreover, serum phosphate levels were at the lower limit of the normal ranges (median: $3.2 \mathrm{mg} / \mathrm{dL}$ ), while serum magnesium levels remained within the normal range (median: $2.3 \mathrm{mg} / \mathrm{dL}$ ). We also observed agerelated high serum alkaline phosphatase levels in most patients (median: 259U/L; reference range for alkaline phosphatase: $37-114 \mathrm{U} / \mathrm{L}$ ). Further, serum creatinine and 25-OH vitamin D levels were within the reference range, excluding renal failure or nutritional $25-\mathrm{OH}$ vitamin $\mathrm{D}$ deficiency. Taken together, these clinical findings suggested primary hyperparathyroidism, but characteristically the study patients exhibited hypocalciuria, which pointed to CASR disorders. Specifically, their median urinary calcium-to-creatinine ratio ( $\mathrm{UCa} / \mathrm{Cr} 0.01 \mathrm{mg} / \mathrm{mg}$ ) was very low despite their high serum calcium levels, and this finding was confirmed by 24 -h urine collection, which also demonstrated low renal calcium excretion (median: $109 \mathrm{mg} / 24 \mathrm{~h}$ ) (Supplementary Table 1, see section on supplementary data given at the end of this article).

Notably, some individuals of the cohort with confirmed CASR-inactivating mutations had hypercalcemia but normal urinary calcium excretion (CA57) or elevated urinary calcium excretion (CA73) or were initially diagnosed with hyperparathyroidism (CA02, CA07, CA19, CA34, CA42 and ME133) (Table 1). For instance, the index case of family CA07 was initially diagnosed at age 56 years with primary hyperparathyroidism due to an abnormally high PTH level $(54 \mathrm{pg} / \mathrm{mL})$ but a normal urinary calcium excretion $(160 \mathrm{mg} / 24 \mathrm{~h})$, and findings in his 51-year-old sister were similar. Further, in some cases, PTH levels were also high. Firstly, proband CA19, diagnosed at 64 years of age, had chondrocalcinosis and osteoporosis, together with hypercalcemia $(11.5 \mathrm{mg} / \mathrm{dL})$ and an abnormally high PTH level $(75 \mathrm{pg} / \mathrm{mL})$. Secondly, the proband of family ME133 presented with vitamin D insufficiency, serum calcium of $10.6 \mathrm{mg} / \mathrm{dL}$ and a high PTH level $(154 \mathrm{pg} / \mathrm{mL})$ and as shown in Fig. 2, the pedigree of this family was unusual (all members assessed having hyperparathyroidism and vitamin D insufficiency, but only two being found to carry a CASR mutation). Both of the aforementioned patients were treated with parathyroidectomy, and parathyroid glands showed hyperplasia in both cases. Moreover, in three additional families (CA34, CA42 and CA02), the index case presented with symptoms of neonatal hyperparathyroidism, at 6 months, 23 and 20 days of age, respectively. In those cases, maternal hypoparathyroidism was excluded. Proband CA34 had a transient episode of primary hyperparathyroidism that normalized spontaneously, while proband CA42 presented with symptoms that are characteristic of neonatal hyperparathyroidism: failure to thrive, hypotonia, constipation, dehydration and lethargy. Moreover, laboratory analysis revealed severe hyperparathyroidism with high levels of PTH $(518 \mathrm{pg} / \mathrm{mL})$ and magnesium $(2.6 \mathrm{mg} / \mathrm{mL})$, together with low levels of 


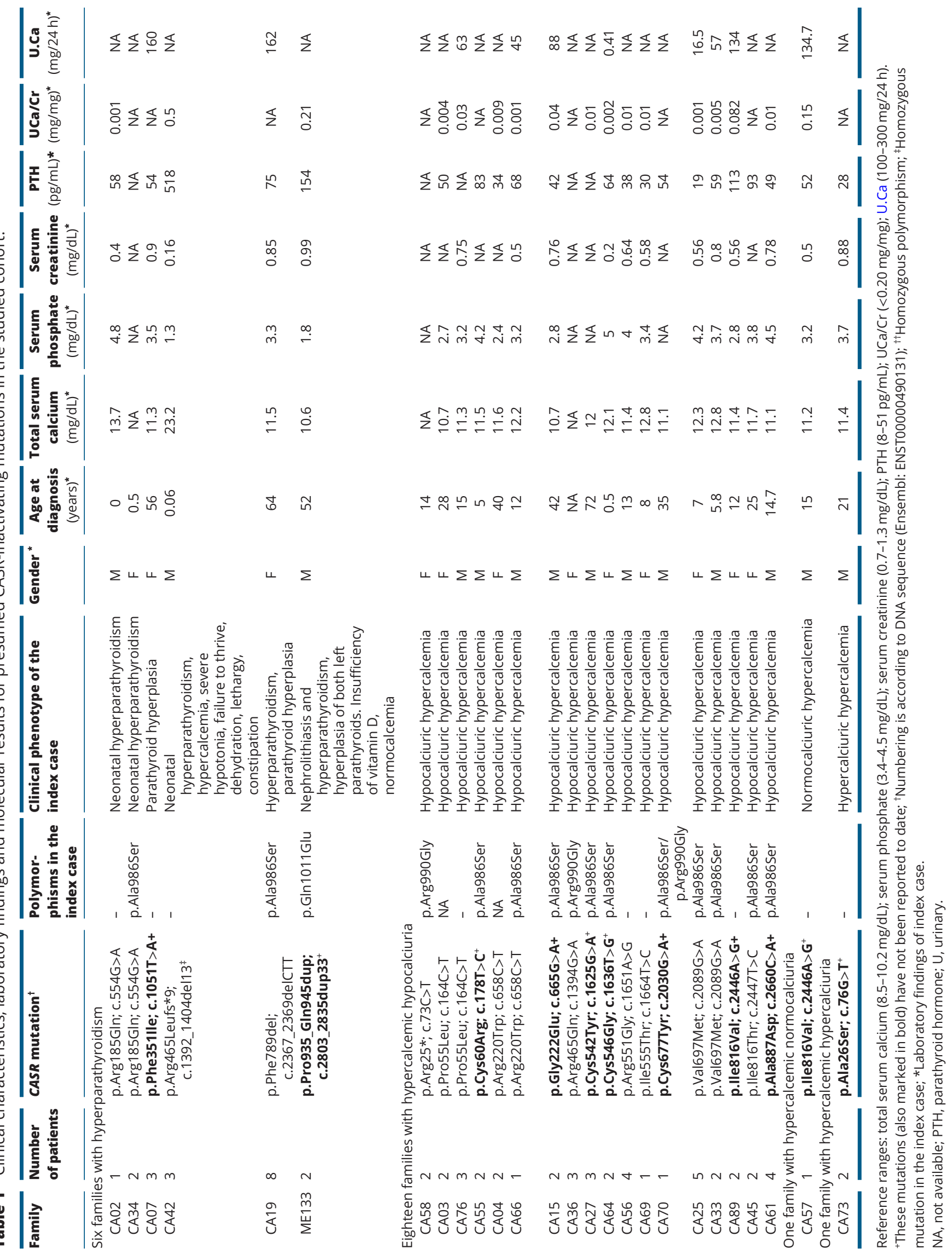


serum phosphate $(1.3 \mathrm{mg} / \mathrm{mL})$ and alkaline phosphatase levels two- to four-fold higher than the normal limit (549 U/L).

In addition, within the subgroup of patients with CaSR-inactivating mutations, we found one case with nephrolithiasis (index case of family ME133). Other manifestations observed in this subgroup were osteopenia in two cases (index cases of families CA03 and CA04), and in one case each: asthenia (index case of family CA33), dizziness and bone lesions (proband CA61) and epilepsy (proband CA25).

Statistical analysis of patients with CaSR-inactivating mutations revealed significant associations between total serum calcium and age at diagnosis $(P<0.01, r=0.38)$ (Fig. 3). In contrast, there was no significant association between the age at diagnosis and PTH $(P>0.05)$ and total serum calcium and PTH $(P>0.05)$.

On the other hand, we found presumed CaSR-activating mutations in 8 out of 18 families (17 patients) with a clinical diagnosis of autosomal dominant hypocalcemia (Table 2). In these patients, the disease was diagnosed at a median of 12 years of age. In most cases, hypocalcemia was an incidental laboratory finding, with a median serum calcium level of $7.4 \mathrm{mg} / \mathrm{dL}$ and hypoparathyroidism (median PTH $13 \mathrm{pg} / \mathrm{mL}$ ) (Fig. 1). Moreover, the mean serum phosphate level was high (median $6.6 \mathrm{mg} / \mathrm{dL}$ ), while the mean serum magnesium level was low or borderline low (median $1.6 \mathrm{mg} / \mathrm{dL}$ ). Characteristically, these patients presented marked hypercalciuria (median $\mathrm{UCa} / \mathrm{Cr} 0.16 \mathrm{mg} / \mathrm{mg}$ ) (Supplementary Table 1). Other findings were tetany and nephrocalcinosis, in the index case of family CA12 (an 11-year-old girl), and renal colic, depression, obesity, acanthosis, hirsutism and mammary hypoplasia, in the index case of family CA23 (a 41-year-old woman). The latter patient had earlier been diagnosed with 21-hydroxylase deficiency and congenital adrenal hyperplasia. She also had diabetes mellitus and nephrolithiasis. Finally, the index case of family CA01 showed intracranial calcifications and hypothyroidism. No significant associations between total serum calcium, PTH and age were observed in this group of patients.

In summary, we observed presumed pathogenic CASR gene variants in 82 out of 130 patients (63\%), from 34 unrelated families that explained patient phenotype. In addition, in 27 patients ( 27 families), we found common polymorphisms that have been previously reported to be linked to abnormally high blood ionized calcium level, and risk of hypercalcemia or colorectal adenoma (12). No other alterations in the CASR gene have been detected in these 27 patients. Finally, no mutations were detected in the other 21 patients ( 21 families). Their laboratory features included elevated serum calcium levels (median $11.4 \mathrm{mg} / \mathrm{dL}$ ) and high intact PTH levels (median $92 \mathrm{pg} /$ $\mathrm{mL}$ ) in 16 patients (with a median age at diagnosis of the disease of 35 years), whereas in five patients, hypocalcemia was found (median $6.7 \mathrm{mg} / \mathrm{dL}$ ) with a median PTH level of $24 \mathrm{pg} / \mathrm{mL}$ (Supplementary Table 1).

Regarding molecular diagnosis, we observed 30 mutations in 34 families: 25 missense, 2 nonsense, 1 gross deletion of 13 nucleotides resulting in a frameshift mutation, 1 small deletion of 3 nucleotides and 1 duplication of 33 nucleotides. Of these, 14 of the pathogenic CASR gene variants were novel. Only the index case of family CA42 was found to be homozygous for the mutation.

In the extracellular domain, we found 19 (63\%) different mutations, 9 of them were novel mutations. We observed more inactivating $(13,14)$ than activating (5) mutations in this part of the receptor. Of these 19 mutations, 13 were in the venus fly trap-like domain, 5 in the cysteine-rich region and 1 in the peptide linker. Eight mutations were found in the transmembrane domain and three mutations in the intracellular domain (carboxylterminal tail).

\section{Discussion}

In this study, we analyzed a cohort of 130 patients with suspected alterations in the CASR gene. We found that 65 patients from 26 families had inactivating mutations and 17 patients from 8 families activating mutations. Overall, in our cohort, 30 different CASR gene mutations were detected and, importantly, the complete genetic study revealed 14 mutations (47\%) not previously reported: (p.Ala26Ser, p.Cys60Arg, p.Lys119Ile, p.Leu123Met, p.Glu133Val, p.Gly222Glu, p.Phe351Ile, p.Cys542Tyr, p.Cys546Gly, p.Cys677Tyr, p.Ile816Val, p.Ala887Asp, p.Gln934* and p.Pro935_Gln945dup). In accordance with previous studies of the CASR gene, we found mutations in the three major regions of the receptor, namely, the extracellular domain, the seven transmembrane domains and the intracellular carboxyl-terminal tail. Unfortunately, one of the limits of our study was the lack of functional analysis; therefore, we are unable to determine whether these changes are responsible for the phenotypes of the patients, especially in the case of novel mutations which we consider 'likely disease-causing mutations'.

Clinical and biochemical findings in the group of patients with inactivating mutations of the CASR gene 

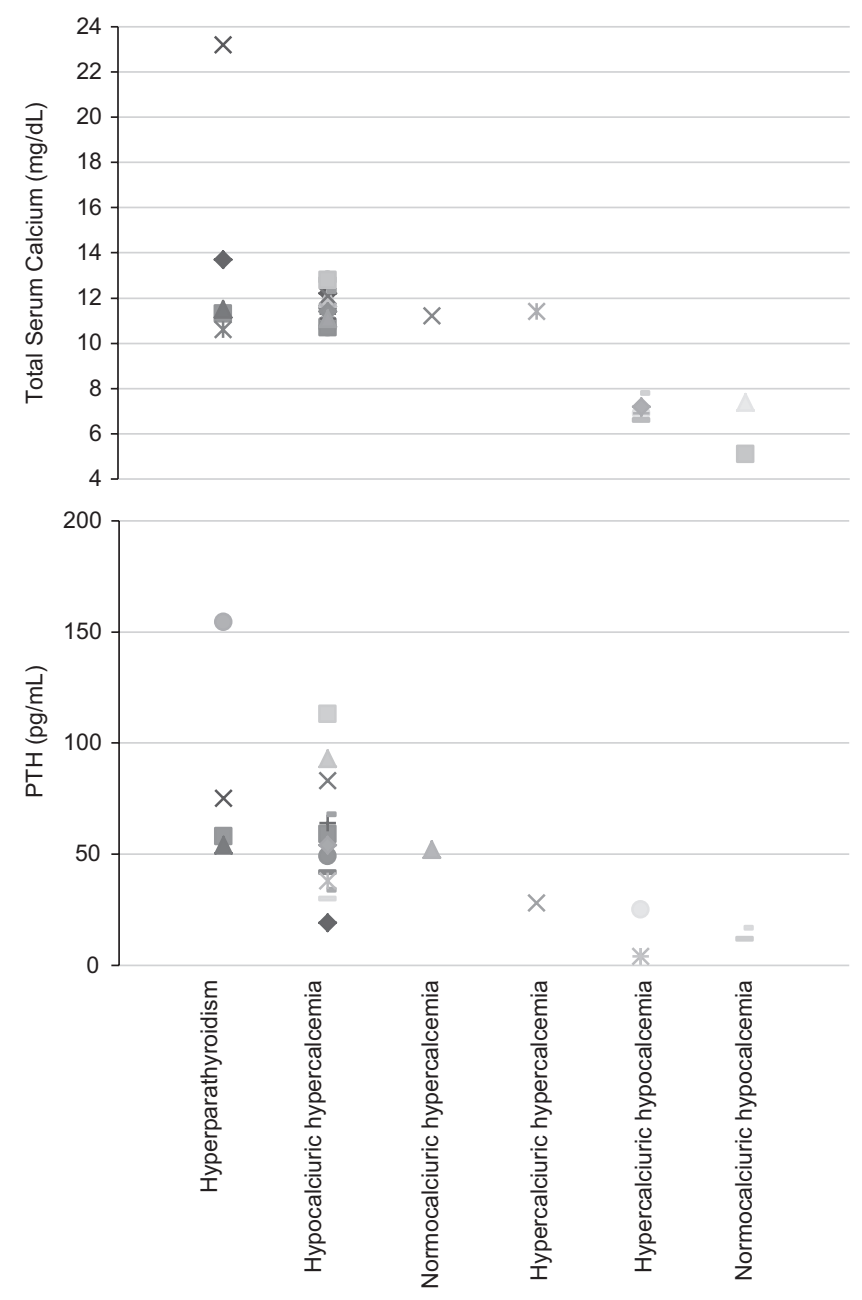

Figure 1

Scatter plots of total serum calcium and parathyroid hormone (PTH) levels for each phenotype observed in our cohort. The reference ranges considered were 8.5-10.2 mg/dL for total serum calcium and $8-51 \mathrm{pg} / \mathrm{mL}$ for PTH. Each patient is represented by a different symbol.

are in concordance with the clinical studies of familial hypocalciuric hypercalcemia undertaken in the $1980 \mathrm{~s}$ by Marx et al. $(13,14)$. We observed that most patients with inactivating mutations have the classic phenotype with hypercalcemia and hypocalciuria; however, in some cases, urinary calcium levels are normal or even high (Supplementary Fig. 1). Furthermore, the biochemical profile varies considerably and this variability is thought to be mutation dependent (15). We observed that the PTH and calcium levels and the urinary calcium-to-creatinine ratio depended on the mutation type (Supplementary Fig. 1).

Specifically, in the extracellular domain, the Ala116Pro136 region was described as an important hot spot for activating mutations (16). We found three novel

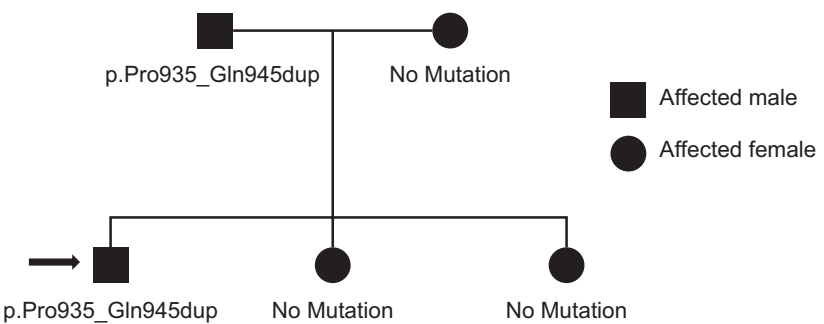

Figure 2

Pedigree of a family (ME133) with hyperparathyroidism. All five family members had normocalcemic hyperparathyroidism but only the proband and his father carried the p.Pro935_ Gln945dup mutation.

mutations in this region (p.Lys119Ile, p.Leu123Met and p.Glu133Val), and all the patients with these mutations had hypocalcemia (Supplementary Fig. 1). On the other hand, several inactivating mutations have been described in the Asp215-Arg227 region that was reported as an important region for ligand-receptor interaction (17). We found two mutations in this region (p.Arg220Trp and p.Gly222Glu). The patients with these mutations had hypercalcemia and hypocalciuria, clinical features compatible with inactivating mutations (Table 1). Another important region in the extracellular domain is the cysteine-rich region, close to the membrane, that is highly conserved. We found four mutations (p.Cys542Tyr, p.Cys546Gly, p.Arg551Gly and p.Ile555Thr) in this region. Again, all the patients had features compatible

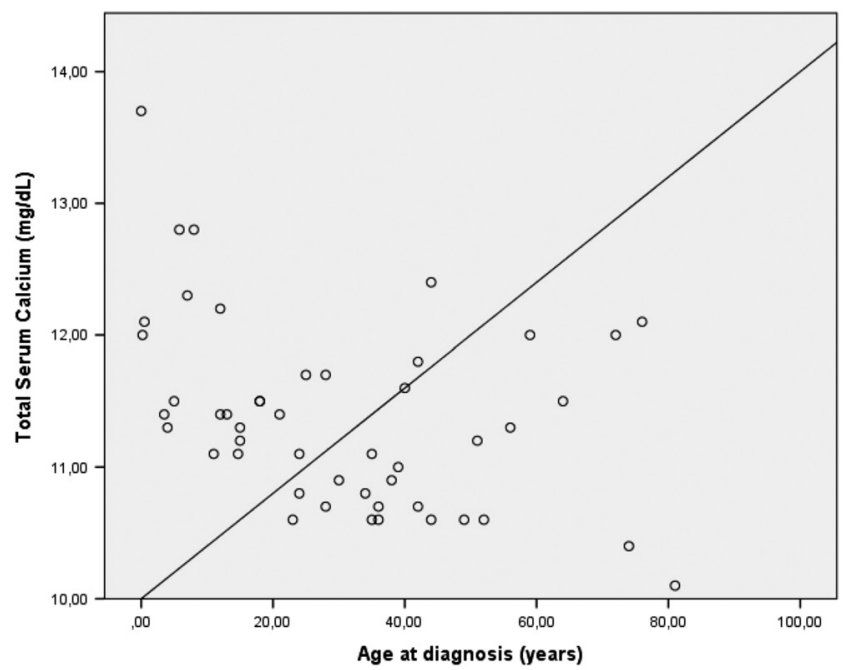

Figure 3

Linear regression calcium and age at diagnosis (b) based on 65 patients with an inactivating mutation in the CASR gene. The correlation is significant $(P<0.01, r=0.38)$. 


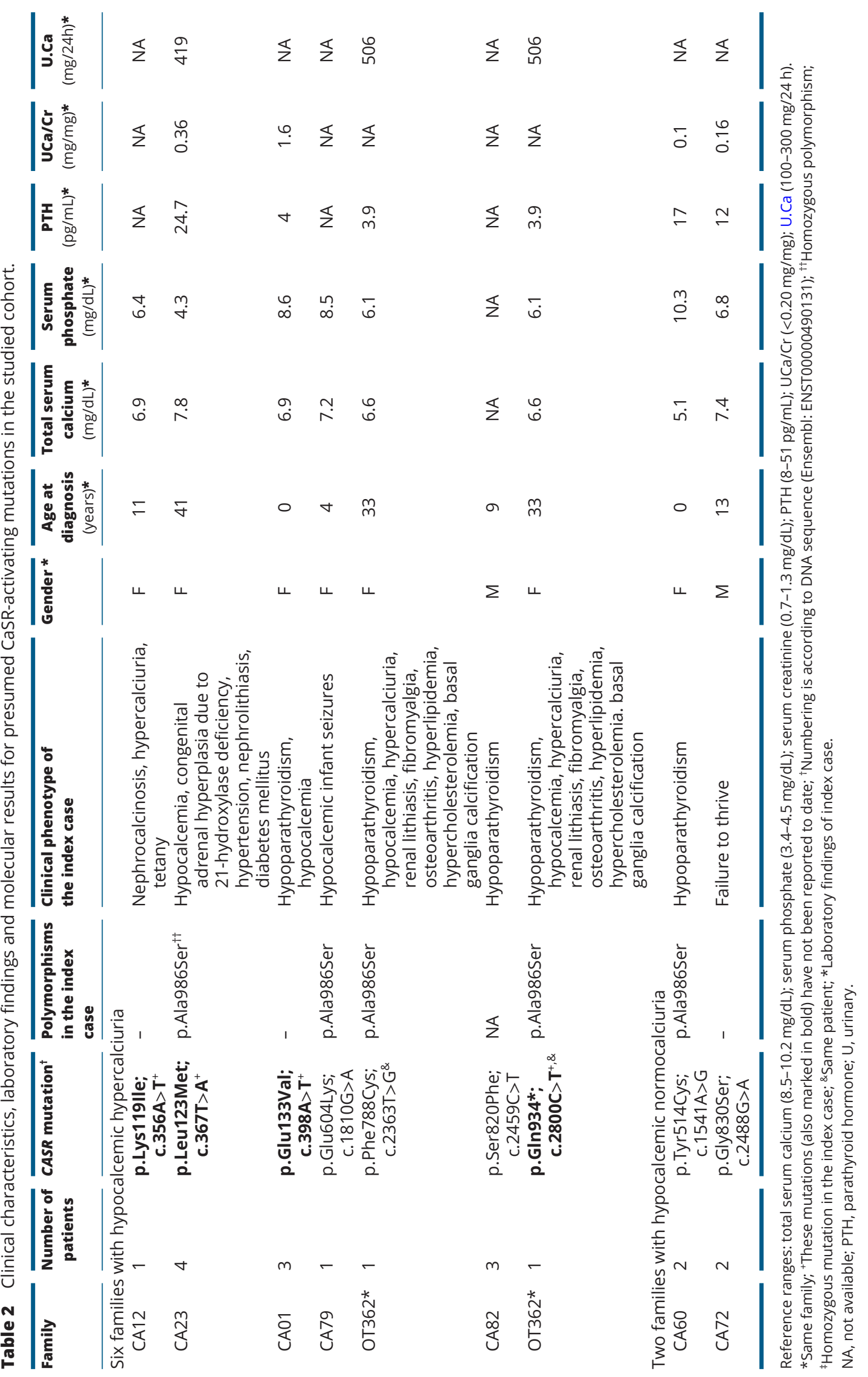


with inactivating mutations. Moreover, many mutations between amino acids 544 and 555 have been described to be associated with an inactivating effect $(17,18)$. In a previous study, Nissen et al. reported another mutation between those described in our study (p.Arg544Gln); however, in that case, in silico analysis predicts a nonpathogenic effect. Our results support the view that this mutation has a pathogenic effect as reported by Nissen et al. and confirm this region as an important hot spot for inactivating mutations (18).

In concordance with other studies, we found both inactivating (p.Cys677Tyr, p.Val697Met, p.Phe789del, p.Ile816Val and p.Ile816Thr) and activating (p.Phe788Cys, p.Ser820Phe and p.Gly830Ser) mutations in the transmembrane domain $(19,20)$.

Loss of part of the intracellular domain presumably results in a non-functional receptor, likely due to its interaction with the $G$ protein being disrupted. On the other hand, phosphorylation sites are located in this region (CaSR being regulated by protein kinase $\mathrm{C}$ phosphorylation), and the elimination of such important sites might cause continuous activation of the receptor (21). In our cohort, patient ME133 with the p.Pro935 Gln945dup duplication in the intracellular domain had hypercalcemia, hypocalciuria and hyperparathyroidism. A similar phenotype was described in another patient who had an insertion of an Alu-repetitive element after codon 877 within the predicted carboxyl-terminal tail of the receptor (22). Therefore, we hypothesize that both mutations yield a truncated protein with loss of the normal CaSR sequence of 1078 amino acids, which probably destabilizes the protein and alters its subcellular localization.

Interestingly, we found one patient (OT362) with two mutations: the p.Phe788Cys mutation (in the transmembrane domain) and the novel p.Gln934* mutation (in the intracellular domain). This patient had hypocalcemia, hypercalciuria and hypoparathyroidism, and therefore, wesuppose that these two mutations together behave as an activating mutation. Unfortunately, we were not able to perform genetic testing in the family or check whether those mutations were present in different alleles. The p.Phe788Cys mutation was described to be associated with hypocalcemia and hypoparathyroidism (23), while functional studies had previously demonstrated that this mutation increases intracellular $\left[\mathrm{Ca}^{2+}\right]$ and activates the calcineurin-nuclear factor of activated $\mathrm{T}$ cell signaling pathway (24). On the other hand, the novel p.GIn934* mutation produces a strongly truncated protein (missing more than $10 \%$ of its amino acids), and, as far as we know, it is the first described nonsense mutation associated with hypocalcemia. A similar activating mutation consisting of a large deletion of 181 amino acids in the carboxylterminal tail (Ser895-V1075) has been reported, and the authors suggested that CaSR with this large deletion exerts a dominant-positive effect in the membrane. Further, more CASRs carrying that deletion than WT CaSRs had been observed on the membrane in heterozygous patients (25).

On the other hand, it was hypothesized that some point mutations exert a dominant-negative effect in the heterozygous state, interfering with the WT receptor signal and, therefore producing a more severe biochemical phenotype (26). Patient CA58, who had the p.Arg25* mutation in the heterozygous state, exhibits a less severe phenotype. We hypothesize that in this patient only WT receptors are expressed in the membrane and that the absence of a defective receptor in the membrane is what explains why the mutant does not exert a dominant-negative effect. On the other hand, the index case of family CA42, who presented the p.Arg465Leufs $* 9$ mutation in the homozygous state, had a more severe phenotype and he had been diagnosed with neonatal hyperparathyroidism. In this patient, we consider it likely that the receptor was not expressed in the membrane. This hypothesis is supported by the fact that patient's parents (who carried the mutation in heterozygous state) had a mild phenotype, similar to that of CA58.

As far as we know, none of the patients in our group of 17 patients with activating mutations had symptoms of Bartter syndrome, such as hypokalemia, secondary hyperaldosteronism or a low fractional chloride reabsorption rate (27).

In our cohort, we found three common variants previously described as polymorphisms in the CASR gene (c.2956G>T; p.Ala986Ser, c.2968A>G; p.Arg990Gly and c.3031C>G; p.Gln1011Glu). The allele frequency of the p.Ala986Ser polymorphism is 0.1269 (according to ExAC, http://exac.broadinstitute.org), being around 0.15 in Caucasians, but very rare in African and East Asian populations (allele frequency of 0.03). This polymorphism has been described associated with hypercalcemia, higher mean serum calcium being observed in individuals with p.Ala986Ser, especially when in the homozygous state, than those without this polymorphism (28). Furthermore, the risk of primary hyperparathyroidism was reported to be higher in some patients (29). We found the p.Ala986Ser polymorphism in 37 patients (in the heterozygous state in 32 cases, in the homozygous state in 3 and in the compound heterozygous state with the polymorphisms 
p.Arg990Gly or p.Gln1011Glu in 2); this polymorphism change was the only alteration found in the CASR gene in 20 of these patients, while 17 (index cases) also carried, besides this polymorphism, other likely disease-causing mutations (activating and/or inactivating) in the CASR gene (Tables 1 and 2). We observed that 29 of these 37 patients had hypercalcemia, including four patients initially diagnosed with hyperparathyroidism, similar to what has been described previously. On the other hand, other studies (which include functional analysis) have reported no relation between the presence of the p.Ala986Ser polymorphism and high levels of serum calcium $(30,31)$. Indeed, we observed eight patients with this polymorphism (including one carrying it in the homozygous state) who had hypocalcemia.

The second polymorphism observed (p.Arg990Gly) has an allele frequency of 0.1451 in the general population and is rare in Europe (0.10) and Africa (0.04), but very common in East Asia (0.50). It has been associated with the risk of chronic pancreatitis (32) and colorectal adenoma, but all previous studies are based on single-nucleotide polymorphism associations, not specifically focusing on the p.Arg990Gly polymorphism (12). Functional analysis showed that the p.Arg990Gly polymorphism produces a gain of function in the receptor (33) with increased hypercalciuria in people who are stone formers (34). In addition, some authors reported that individuals with this polymorphism and primary or secondary hyperparathyroidism had lower levels of serum PTH and ionized calcium (35). We found eight patients with the p.Arg990Gly polymorphism in our cohort: three of them also had inactivating mutations in the CASR gene (Table 1), while in the other five patients, we observed that two had hypocalcemia, hypoparathyroidism and hypercalciuria, in accordance with receptor gain of function, but the other three had hypercalcemia.

The last polymorphism (c.3031C>G; p.Gln1011Glu) studied has an allele frequency of 0.0554 , and it was associated with higher blood ionized calcium levels (34). In our cohort, we found three patients with this polymorphism: one had another mutation in the CASR gene (Table 1), whereas the other two had hypercalcemia with hypocalciuria. As mentioned previously, other studies have reported no relation between these three polymorphisms and calcium homeostasis $(30,31)$.

Further work would be necessary to clarify whether these polymorphisms cause significant variations in calcium homeostasis or are risk factors for the development of primary hyperparathyroidism in these 27 patients without any other alteration in the CASR gene.
Finally, in 21 patients, no alterations were found by sequencing the CASR gene. Hence, the next step in our analysis of these patients will be to study four genes associated with calcium homeostasis disorders: the GNA11 gene, encoding the alpha subunit of Ga11 (36); the AP2S1 gene, encoding the adaptor-protein 2 sigma subunit (37); the CYP24A1 gene, encoding a member of the cytochrome P450 superfamily and the SLC34A1 gene, encoding a member of the type II sodium-phosphate cotransporter family $(38,39)$.

In conclusion, patients with inactivating mutations of the CASR gene may not present a classic picture of hypercalcemia with hypocalciuria, and in fact, their urinary calcium levels may be normal (Supplementary Fig. 1). Variations in calcium excretion can be due to many factors, including dietary intake of salt and animal proteins (40). Given this, molecular studies are not only important for confirming the diagnosis and distinguish it from other entities, but also essential for detecting carriers, as some individuals with mutations may remain normocalcemic. In the clinical setting, it can be difficult to differentiate hypocalciuric hypercalcemia type I from primary hyperparathyroidism (for which surgery may well be performed) and autosomal dominant hypocalcemia from idiopathic hypoparathyroidism, because of common biochemical features. In addition, understanding the functional impact of the mutations at the cell membrane is critical for guiding pharmacological research, and could facilitate individualized treatment of patients in the future. Moreover, our study supports the results observed by other groups concerning the dominant effect of some mutations in the heterozygous state and the pathogenicity of some other mutations despite in silico predictions of a non-pathogenic effect.

We believe that this comprehensive genetic and clinical description of a cohort of 82 patients with presumably activating or inactivating mutations will help improve our understanding of the function of given structures in the CASR. Nevertheless, we recognized the need to conduct functional analysis to confirm the pathogenicity of our novel mutations.

\section{Supplementary data}

This is linked to the online version of the paper at https://doi.org/10.1530/ EJE-18-0129.

Declaration of interest

The authors declare that there is no conflict of interest that could be perceived as prejudicing the impartiality of this study. 


\section{Funding}

This study was supported by a grant from the Departments of Health (2014111064) and of Education (IT795-13) of the Basque Government. The funders had no role in study design, data collection and analysis, decision to publish or preparation of the manuscript.

\section{Author contribution statement}

Writing: A G-C, L M, L C, G A, S G. Conceptualization: A G-C, L M, L C, G A, $S$ G. Formal analysis: $A G-C, G P d N$. Funding acquisition: $L M, L C, G A$. Investigation: A G-C, L M, G P d N, LC, G A, S G. Methodology: A G-C, G P, LC. Project administration: $L M, L C, G$. Resources: $L M, L C, G A$. Visualization: A G-C, L M, L C, G A, S G. Clinical diagnostic and validation: A G-C, L M, S G, $L C, G A, J R, M G, C M, R R, C S, M B, C A, I B, S C, B$ G-C, B J, P R, E P, E H-B, R $B, C M G, C L R C$, J C, J H, C F-R, J M, M C, L G, I R, R M, I U, I M d L, F S, H G-P, EC, V L, FÁ O, JR, E B R, O H, R F, D C, V M G N, FCM, H G A, ERT, M I LY, $E C L, M A, M H, A A, A M$.

\section{Acknowledgements}

The authors thank patients and families and their pediatric nephrologists and endocrinologists who collaborated with the genetic study. They are grateful to the RenalTube group for contributing samples for this study. Spanish Endocrinology Group: Joaquín Ramírez, Mercedes Gómez (Hospital Universitario Príncipe de Asturias - Madrid), Coral Montalbán (Hospital Sierrallana - Torrelavega), Rafael Ruiz (Complejo Hospitalario Universitario - Albacete), Catalina Socias (Hospital Bidasoa - Hondarribia), Mauro Boronat (Complejo Hospitalario Universitario Insular Materno-Infantil - Las Palmas de Gran Canaria), Cristina Aparicio (Hospital Universitario - Getafe), Ismene Bilbao (Hospital Universitario - Donostia), Santiago Conde (Hospital de Barbastro - Huesca), Beatriz García-Cuartero (Hospital Universitario Severo Ochoa - Leganés), Belén Jiménez, Pilar Rodríguez (Hospital Juan Ramón Jiménez - Huelva), Elena Pérez (Hospital Universitario Virgen Macarena - Sevilla), Emilia Hidalgo-Barquero (Hospital Materno Infantil - Badajoz), Raquel Barrio (Hospital Universitario Ramón y Cajal Madrid), Carmen María González (Hospital Rafael Méndez - Lorca), Carmen Lourdes Rey Cordo (Complejo Hospitalario Universitario - Vigo), Jaime Cruz (Hospital Universitario 12 de Octubre - Madrid), Jorge Hernández (Hospital de Galdakao), Concepción Fernández-Ramos (Hospital Universitario Basurto - Bilbao), Juan Martí (Hospital de Zumárraga), María Clemente (Hospital Universitario Vall d'Hebron - Barcelona), Leonor García (Hospital de Sagunto), Itxaso Rica, Rosa Martínez, Inés Urrutia, Idoia Martínez de LaPiscina (Hospital Universitario Cruces, Biocruces Bizkaia Health Research Institute - Barakaldo). RenalTube Group: Fernando Santos, Helena GilPeña, Eliecer Coto, Vanessa Loredo, Flor Ángel Ordóñez, Julián Rodríguez, Eva Braga Riera, Olaya Hernández, Rocío Fuente, Débora Claramunt (Hospital Universitario Central de Asturias - Oviedo). Víctor M. García Nieto, Félix Claverie Martín, Hilaria González Acosta, Elena Ramos Trujillo, María Isabel Luis Yanes, Elizabeth Córdoba Lanús (Hospital Universitario Nuestra Señora de Candelaria - Tenerife). Luis Castaño, Leire Madariaga, Gustavo Pérez de Nanclares, Alejandro García-Castaño, Mireia Aguirre, María Herrero, Aníbal Aguayo (Hospital Universitario Cruces - Barakaldo). Gema Ariceta, Anna Meseguer (Hospital Universitario Materno-Infantil Vall d'Hebron - Barcelona).

\section{References}

1 Aida K, Koishi S, Tawata M \& Onaya T. Molecular cloning of a putative $\mathrm{Ca}(2+)$-sensing receptor cDNA from human kidney. Biochemical and Biophysical Research Communications 1995214 524-529. (https://doi.org/10.1006/bbrc.1995.2318)

2 Brown EM, Gamba G, Riccardi D, Lombardi M, Butters R, Kifor O, Sun A, Hediger MA, Lytton J \& Hebert SC. Cloning and characterization of an extracellular $\mathrm{Ca}(2+)$-sensing receptor from bovine parathyroid. Nature 1993366 575-580. (https://doi. org/10.1038/366575a0)

3 Brown EM. Role of the calcium-sensing receptor in extracellular calcium homeostasis. Best Practice and Research: Clinical Endocrinology and Metabolism 201327 333-343. (https://doi.org/10.1016/j. beem.2013.02.006)

4 Nemeth EF \& Scarpa A. Rapid mobilization of cellular Ca2+ in bovine parathyroid cells evoked by extracellular divalent cations. Evidence for a cell surface calcium receptor. Journal of Biological Chemistry 1987 262 5188-5196.

5 Freichel M, Zink-Lorenz A, Holloschi A, Hafner M, Flockerzi V $\&$ Raue F. Expression of a calcium-sensing receptor in a human medullary thyroid carcinoma cell line and its contribution to calcitonin secretion. Endocrinology 1996137 3842-3848. (https://doi. org/10.1210/endo.137.9.8756555)

6 Marie PJ. The calcium-sensing receptor in bone cells: a potential therapeutic target in osteoporosis. Bone 201046 571-576. (https:// doi.org/10.1016/j.bone.2009.07.082)

7 Carling T, Szabo E, Bai M, Ridefelt P, Westin G, Gustavsson P, Trivedi S, Hellman P, Brown EM, Dahl N et al. Familial hypercalcemia and hypercalciuria caused by a novel mutation in the cytoplasmic tail of the calcium receptor. Journal of Clinical Endocrinology and Metabolism 200085 2042-2047. (https://doi.org/10.1210/ jcem.85.5.6477)

8 Grzegorzewska AE, Paciorkowski M, Mostowska A, Frycz B, Warchoł W, Stolarek I, Figlerowicz M \& Jagodziński PP. Associations of the calcium-sensing receptor gene CASR rs7652589 SNP with nephrolithiasis and secondary hyperparathyroidism in haemodialysis patients. Scientific Reports 20166 35188. (https://doi.org/10.1038/ srep35188)

9 Janicic N, Soliman E, Pausova Z, Seldin MF, Rivière M, Szpirer J, Szpirer C \& Hendy GN. Mapping of the calcium-sensing receptor gene (CASR) to human chromosome 3q13.3-21 by fluorescence in situ hybridization, and localization to rat chromosome 11 and mouse chromosome 16. Mammalian Genome 19956 798-801. (https://doi. org/10.1007/BF00539007)

10 Vezzoli G, Soldati L \& Gambaro G. Roles of calcium-sensing receptor (CaSR) in renal mineral ion transport. Current Pharmaceutical Biotechnology 200910 302-310. (https://doi. org/10.2174/138920109787847475)

11 Conigrave AD \& Ward DT. Calcium-sensing receptor (CaSR): pharmacological properties and signaling pathways. Best Practice and Research: Clinical Endocrinology and Metabolism 201327 315-331. (https://doi.org/10.1016/j.beem.2013.05.010)

12 Peters U, Chatterjee N, Yeager M, Chanock SJ, Schoen RE, McGlynn KA, Church TR, Weissfeld JL, Schatzkin A \& Hayes RB. Association of genetic variants in the calcium-sensing receptor with risk of colorectal adenoma. Cancer Epidemiology, Biomarkers and Prevention 200413 2181-2186.

13 Marx SJ, Spiegel AM, Brown EM \& Aurbach GD. Family studies in patients with primary parathyroid hyperplasia. American Journal of Medicine 197762 698-706. (https://doi.org/10.1016/00029343(77)90873-7)

14 Attie MF, Gill JR Jr, Stock JL, Spiegel AM, Downs RW Jr, Levine MA \& Marx SJ. Urinary calcium excretion in familial hypocalciuric hypercalcemia. Persistence of relative hypocalciuria after induction of hypoparathyroidism. Journal of Clinical Investigation $1983 \mathbf{7 2}$ 667-676. (https://doi.org/10.1172/JCI111016)

15 Gunn IR \& Gaffney D. Clinical and laboratory features of calcium-sensing receptor disorders: a systematic review. Annals of Clinical Biochemistry 200441 (Pt 6) 441-458. (https://doi. org/10.1258/0004563042466802)

16 Jensen AA, Spalding TA, Burstein ES, Sheppard PO, O'Hara PJ, Brann MR, Krogsgaard-Larsen P \& Bräuner-Osborne H. Functional importance of the Ala(116)-Pro(136) region in the calcium-sensing 
receptor. Constitutive activity and inverse agonism in a family $\mathrm{C}$ G-protein-coupled receptor. Journal of Biological Chemistry 2000275 29547-29555. (https://doi.org/10.1074/jbc.M910023199)(https;//doi. org/10.1210/jcem.87.3.8280)

17 D'Souza-Li L, Yang B, Canaff L, Bai M, Hanley DA, Bastepe M, Salisbury SR, Brown EM, Cole DE \& Hendy GN. Identification and functional characterization of novel calcium-sensing receptor mutations in familial hypocalciuric hypercalcemia and autosomal dominant hypocalcemia. Journal of Clinical Endocrinology and Metabolism 200287 1309-1318.

18 Nissen PH, Christensen SE, Ladefoged SA, Brixen K, Heickendorff L \& Mosekilde L. Identification of rare and frequent variants of the CASR gene by high-resolution melting. Clinica Chimica Acta 2012413 605-611. (https://doi.org/10.1016/j.cca.2011.12.004)

19 Aparicio López C, Anton-Martin P, Gil-Fournier B, Ramiro-León S, PérezNanclares G, Pérez de Nanclares G, Martínez Menéndez B \& Castaño L. Familial hypocalciuric hypercalcemia: new mutation in the CASR gene converting valine 697 to methionine. European Journal of Pediatrics 2012 171 147-150. (https://doi.org/10.1007/s00431-011-1504-8)

20 Letz S, Rus R, Haag C, Dörr HG, Schnabel D, Möhlig M, Schulze E, Frank-Raue K, Raue F, Mayr B et al. Novel activating mutations of the calcium-sensing receptor: the calcilytic NPS-2143 mitigates excessive signal transduction of mutant receptors. Journal of Clinical Endocrinology and Metabolism 201095 E229-E233. (https://doi. org/10.1210/jc.2010-0651)

21 Bai M, Pearce SH, Kifor O, Trivedi S, Stauffer UG, Thakker RV, Brown EM \& Steinmann B. In vivo and in vitro characterization of neonatal hyperparathyroidism resulting from a de novo, heterozygous mutation in the $\mathrm{Ca} 2+$-sensing receptor gene: normal maternal calcium homeostasis as a cause of secondary hyperparathyroidism in familial benign hypocalciuric hypercalcemia. Journal of Clinical Investigation 199799 88-96. (https://doi. org/10.1172/JCI119137)

22 Cole DE, Janicic N, Salisbury SR \& Hendy GN. Neonatal severe hyperparathyroidism, secondary hyperparathyroidism, and familial hypocalciuric hypercalcemia: multiple different phenotypes associated with an inactivating Alu insertion mutation of the calcium-sensing receptor gene. American Journal of Medical Genetics 199771 202-210. (https://doi.org/10.1002/(SICI)10968628(19970808)71:2<202::AID-AJMG16>3.0.CO;2-I)

23 Watanabe T, Bai M, Lane CR, Matsumoto S, Minamitani K, Minagawa M, Niimi H, Brown EM \& Yasuda T. Familial hypoparathyroidism: identification of a novel gain of function mutation in transmembrane domain 5 of the calcium-sensing receptor. Journal of Clinical Endocrinology and Metabolism $1998 \mathbf{8 3}$ 2497-2502. (https://doi.org/10.1210/jcem.83.7.4920)

24 Kinoshita Y, Hori M, Taguchi M, Watanabe S \& Fukumoto S. Functional activities of mutant calcium-sensing receptors determine clinical presentations in patients with autosomal dominant hypocalcemia. Journal of Clinical Endocrinology and Metabolism 2014 99 E363-E368. (https://doi.org/10.1210/jc.2013-3430)

25 Lienhardt A, Garabédian M, Bai M, Sinding C, Zhang Z, Lagarde JP, Boulesteix J, Rigaud M, Brown EM \& Kottler ML. A large homozygous or heterozygous in-frame deletion within the calcium-sensing receptor's carboxylterminal cytoplasmic tail that causes autosomal dominant hypocalcemia. Journal of Clinical Endocrinology and Metabolism 200085 1695-1702. (https://doi.org/10.1210/ jcem.85.4.6570)

26 Ward BK, Magno AL, Blitvich BJ, Rea AJ, Stuckey BG, Walsh JP \& Ratajczak T. Novel mutations in the calcium-sensing receptor gene associated with biochemical and functional differences in familial hypocalciuric hypercalcaemia. Clinical Endocrinology $2006 \mathbf{6 4}$ 580-587. (https://doi.org/10.1111/j.1365-2265.2006.02512.x)

27 Vargas-Poussou R, Huang C, Hulin P, Houillier P, Jeunemaître X, Paillard M, Planelles G, Déchaux M, Miller RT \& Antignac C.
Functional characterization of a calcium-sensing receptor mutation in severe autosomal dominant hypocalcemia with a Bartter-like syndrome. Journal of the American Society of Nephrology 200213 2259-2266. (https://doi.org/10.1097/01. ASN.0000025781.16723.68)

28 Cole DEC, Vieth R, Trang HM, Wong BYL, Hendy GN \& Rubin LA. Association between total serum calcium and the A986S polymorphism of the calcium-sensing receptor gene. Molecular Genetics and Metabolism 200172 168-74. (https://doi.org/10.1006/ mgme.2000.3126)

29 Wang XM, Wu YW, Li ZJ, Zhao XH, Lv SM \& Wang XH. Polymorphisms of CASR gene increase the risk of primary hyperparathyroidism. Journal of Endocrinological Investigation 2016 39 617-625. (https://doi.org/10.1007/s40618-015-0405-5)

30 Cetani F, Borsari S, Vignali E, Pardi E, Picone A, Cianferotti L, Rossi G, Miccoli P, Pinchera A \& Marcocci C. Calcium-sensing receptor gene polymorphisms in primary hyperparathyroidism. Journal of Endocrinological Investigation 200225 614-619. (https://doi. org/10.1007/BF03345085)

31 Harding B, Curley AJ, Hannan FM, Christie PT, Bowl MR, Turner JJ, Barber M, Gillham-Nasenya I, Hampson G, Spector TD et al. Functional characterization of calcium sensing receptor polymorphisms and absence of association with indices of calcium homeostasis and bone mineral density. Clinical Endocrinology 200665 598-605. (https://doi.org/10.1111/ j.1365-2265.2006.02634.x)

32 Muddana V, Lamb J, Greer JB, Elinoff B, Hawes RH, Cotton PB, Anderson MA, Brand RE, Slivka A \& Whitcomb DC. Association between calcium sensing receptor gene polymorphisms and chronic pancreatitis in a US population: role of serine protease inhibitor Kazal 1type and alcohol. World Journal of Gastroenterology 200814 4486-4491. (https://doi.org/10.3748/wjg.14.4486)

33 Vezzoli G, Terranegra A, Arcidiacono T, Biasion R, Coviello D, Syren ML, Paloschi V, Giannini S, Mignogna G, Rubinacci A et al. R990G polymorphism of calcium-sensing receptor does produce a gain-of-function and predispose to primary hypercalciuria. Kidney International $2007 \mathbf{7 1}$ 1155-1162. (https://doi.org/10.1038/ sj.ki.5002156)

34 Scillitani A, Guarnieri V, De Geronimo S, Muscarella LA, Battista C, D'Agruma L, Bertoldo F, Florio C, Minisola S, Hendy GN et al. Blood ionized calcium is associated with clustered polymorphisms in the carboxyl-terminal tail of the calcium-sensing receptor. Journal of Clinical Endocrinology and Metabolism 200489 5634-5638. (https:// doi.org/10.1210/jc.2004-0129)

35 Terranegra A, Ferraretto A, Dogliotti E, Scarpellini M, Corbetta S, Barbieri AM, Spada A, Arcidiacono T, Rainone F, Aloia A et al. Calcimimetic R-568 effects on activity of R990G polymorphism of calcium-sensing receptor. Journal of Molecular Endocrinology 201045 245-256. (https://doi.org/10.1677/JME-10-0034)

36 Nesbit MA, Hannan FM, Howles SA, Reed AA, Cranston T, Thakker CE, Gregory L, Rimmer AJ, Rust N, Graham U et al. Mutations in AP2S1 cause familial hypocalciuric hypercalcemia type 3. Nature Genetics 201345 93-97. (https://doi.org/10.1038/ ng.2492)

37 Nesbit MA, Hannan FM, Howles SA, Babinsky VN, Head RA, Cranston T, Rust N, Hobbs MR, Heath H 3rd \& Thakker RV. Mutations affecting G-protein subunit $\alpha 11$ in hypercalcemia and hypocalcemia. New England Journal of Medicine 2013368 2476-2486. (https://doi.org/10.1056/NEJMoa1300253)

38 Schlingmann KP, Ruminska J, Kaufmann M, Dursun I, Patti M, Kranz B, Pronicka E, Ciara E, Akcay T, Bulus D et al. AutosomalRecessive Mutations in SLC34A1 Encoding Sodium-Phosphate Cotransporter 2A Cause Idiopathic Infantile Hypercalcemia. Journal of the American Society of Nephrology 201627 604-614. (https://doi. org/10.1681/ASN.2014101025) 
39 Pronicka E, Ciara E, Halat P, Janiec A, Wójcik M, Rowińska E, Rokicki D, Płudowski P, Wojciechowska E, Wierzbicka A et al. Biallelic mutations in CYP24A1 or SLC34A1 as a cause of infantile idiopathic hypercalcemia (IIH) with vitamin D hypersensitivity: molecular study of 11 historical IIH cases.
Journal of Applied Genetics 201758 349-353. (https://doi. org/10.1007/s13353-017-0397-2)

40 Saxena A \& Sharma RK. Nutritional aspect of nephrolithiasis. Indian Journal of Urology 201026 523-530. (https://doi.org/10.4103/0970$1591.74451)$

Received 11 February 2018

Revised version received 3 August 2018

Accepted 6 September 2018 